\title{
Indoor airborne mycobiota of intensive care units in Assiut University Hospitals
}

\author{
M. B. Aboul-Nasr ${ }^{1}$, Abdel-Naser A. El-Zoohri ${ }^{2}$, and Enas M. Amer ${ }^{2}$ \\ ${ }^{1}$ Faculty of Science, Department of Botany, University of Sohag. \\ ${ }^{2}$ Faculty of Science, Department of Botany, University of Assiut.
}

Rec. 3 Jan, 2012 Accpt. 5 Feb, 2012

\begin{abstract}
Contamination of the air by fungi in the intensive care units (ICU) in Assiut university hospitals was investigated. Air samples were collected using settle plate method using four types of media with Rose Bengal-Streptomycin Agar. The mycobiota was isolated and identified. Cladosporium spp., Aspergillus spp., Penicillium spp., Fusarium were recorded most prevalent genera, whereas; Alternaria and Scopulariopsis were found to be with moderate frequency level. Botryotricum, Circinella, Drechslera, Epicoccum, Ulocladium, and others were recorded as the least fungal contaminants. The Aspergillus genus showed the greatest spectrum by being represented by 17 species followed by Penicillium (five species) .Each of Cladosporium, Fusarium and Scopulariopsis was represented by two species while the remaining 18 genera were represented by only one species for each genus. The gross total fungal counts of air born fungi recovered were 1009, 858, 1236 and $1366 \mathrm{cfu} / 72$ plates on the four types of media used ( 24 exposures, 5 minutes for each exposure).

These data revealed that patients of I.C.U. in Assiut university hospitals may be in high risk due to being exposed to atmospheric air highly contaminated by those opportunistic fungal genera that may be deadly to immuno-comprmised individuals who must remain away from any airborne fungal contaminants.
\end{abstract}

Key words: Airborne fungi, Opportunistic fungi, Mycobiota

\section{Introduction}

Airborne microflora in hospital rooms was the subject of numerous studies as a potential cause of hospital infections (Gould et al., 1970; Herman et al., 1980; Kelsen et al., 1980; Rainer et al., 2001 and Li et al., 2003). Some hospital infections are caused by fungi, such as species of Aspergillus, Fusarium or Mucorales (Alberti et al., 2001; Faure et al., 2002 and Perdelli et al., 2006). Indeed, fungi present in hospital rooms may grow on the organic matter of building materials and develop microcolonies. The spores emanating from these colonies could be inhaled by immunosupressed patients and cause local infections, prior to possible dissemination (singh \& Paterson, 2005).

The levels of nosocomial pathogens in the air of hospital increase due to dirtiness of air ducts by operation of the Heating, Ventilating and Air Conditioning (HVAC) system without its regular replacement (Anderson et al., 1996). organic materials such as food, flower and fruit derived from outdoor environment by visitors and contamination of the interior structures by oldness of hospital (Schabrun et al., 2006).

Biological contamination of indoor air is mostly caused by bacteria, moulds and yeast. They can be dangerous as pathogenic living cells but they can also secrete some health hazared materials such as mycotoxins (Flannigan et al., 2001; Piecko et al., 2002 and Daisey et al., 2003). Fungi grow on organic matter surfaces, and their spores are dispersed in the air. While they are ubiquitous in the environment, and apparently harmless to healthy people, they can be deadly to immunocompromised individuals (Kuhn et al., 2003). It is important that hospital rooms (HR) where immunocompromised patients (e.g. transplant recipient, HIV-infected or cancer patients) are placed and operating theatres (OT) remain free of airborne, opportunistic fungi. Aspergillus moulds are ubiquitous, and invasive aspergillosis is the most common mould infection (Vanden et al., 1999).

\footnotetext{
* Corresponding author:

Dr. M. B. Aboul-Nasr

$\triangle$ mbaboulnasr@hotmail.com
} 


\section{Materials and Methodes}

Settle plate method (Hoekstra et al., 2004). was used to catch air-borne fungal species in the atmospheres of the airconditioned rooms of 12 intensive care units at Assiut university hospitals during the period from June 2008 to May 2010. Four types of agar media were used for isolation of fungi (Sabouraud dextrose, Czapek's glucose, Czapek's glucose at $\mathrm{pH} 8.5$, and Czapek's Cellulose agar media). Three plates of each medium were used in each room in each of 24 exposure time. Five minutes exposure time was found as an optimal time for catching a reasonable and countable number of colony forming units in intensive care units. Plates were then brought to the laboratory and incubated at $25^{\circ} \mathrm{C} \pm 2$ for 7-10 days. Total fungal catch (TFC) for each fungus in the twenty four individual exposures (one for each month) were calculated as the number of colonies in each room.

\section{Results}

The gross total fungal counts of air born fungi recovered from 24 individual exposures in the atmosphere of different 12 air conditioned ICU in Assiut university hospitals (two exposures for each) on Czapek's glucose, Czapek's glucose at pH 85, Sabouraud dextrose and Czapek's Cellulose agar media grown at $25 \pm 2{ }^{\circ} \mathrm{C}$ for 7-10 days were $1009,858,1236$ and $1366 \mathrm{cfu} / 72$ plates (24 exposures, 5 minutes for each exposure), respectively Thirty seven Species belonging to 16 fungal genera were collected and identified using all the four above media

Taxa isolated are assigned to three taxonomic groups: Ascomycetes, Hyphomycetes and Zygomycetes The first group was represented by only one species ( $E$ amestelodami) belonging to one genus (Eurotium) with percentage of $217 \%$ from the total number of fungal species The second group was the greatest number of species and represented by 40 species belonging to 17 genera accounting for 8696 $\%$ of the total number of fungal species and finally, Zygomycetes that was represented by five species belonging to five genera with percentage of $1087 \%$ from the total number of fungal species .

View on the diversity of generic level revealed that the Aspergillus genus showed the greatest spectrum by being represented by 17 species followed by Penicillium (five species) .Each of Cladosporium, Fusarium and Scopulariopsis was represented by two species while the remaining 18 genera were represented by only one species for each genus.

Eurotium amstelodami was appeared in only one case of isolation on cellulose medium.

The isolated Aspergillus species are belonging to 10 sections as described by Klich and Pitt (1992). Sections Nigri and Circumdati showed the greatest spectra (three species for each) Sections Flavi, Terrei and Versicolores were represented by two species for each while each of the other five sections (Candidi, Flavipes, Fumigati, Usti and Wentii) was represented by only one species. It was appeared with high frequency on all media used as airborne fungus. Frequencies of this genus were ranged from 66.67 to $100 \%$ and its densities fluctuated between 0.24-16.8\%. Aspergillus flavus, A. fumigates, A. awamori, A. niger and $A$. ochraceous, A. sydowii were isolated from I.C.U. on all mycological media used but with different frequencies and densities. Each of A. aculeatus, A. candidus and A. sulphureus were recorded on sabouraud and cellulose agar media only.

Penicillium was represented by five species belonging to three subgenera as described by Pitt (1979) Subgenus Furcatum and Penicillium represented by two species each while subgenus Biverticillium represented by only one species. It was isolated as airborne fungus. It was represented by five species $(P$. chrysogenum, $P$. corylophilum, $P$. duclauxi, $P$. italicum and $P$. oxalicum). It was isolated with high or moderate frequencies in I.C.U. using the different mycological media. Its densities were ranged from 1.49 to $5.66 \%$ while their frequencies fluctuated between 33.33$62.50 \%$.

Cladosporium was recorded with very high densities and frequencies in all the time of exposures in the atmosphere of all the 12 I.C.U. It was appeared with densities ranged from $43.04-80.3 \%$. It was represented by $C$. cladosporioides and $C$. herbarum. The both species were isolated with high densities in 
$100 \%$ of isolation cases. Fusarium was appeared with low densities and moderate or high frequencies in all cases. Their densities were ranged from 0.93-3.44\%. Alternaria alternata was isolated with high frequencies on Czapek's with pH 8.5 \& Czapek's cellulose media and with moderate \& low frequencies on Czapek's \& sabouraud media, respectively, as airborne fungi in I.C.U. Stachybotrys elegans was recorded with moderate frequency on Czapek's at $\mathrm{pH} 8.5$ and low on the other three media used from the air of I.C.U.

Scopulariopsis (S. brevicaulis and $S$. brumptii) and Stemphylium vesicarium were isolated as airborne fungi. Also, each of Acremonium strictum, Drechslera spicifera, Epicoccum nigrum and Myrothecium roridium were appeared as airborne fungi but with less densities and frequencies. Ulocladium atrum was recorded with low or rare frequencies on the four media used, while Botryotricum piluliferum was appeared with rare occurrence on only two types of the media.

Rhizopus stolinifer was appeared with moderate, low or rare frequencies and low desities in I.C.U. Circinella muscae was recorded only in one case of isolation on sabouraud medium. Finally, Absidia corymbifera was appeared in only one case in I.C.U. on Czapek's medium.

\section{Discussion}

A great concern has been given to the presence of airborne fungi in the hospitals as general or inside intensive care units and operation rooms in different parts of the world such as: France (Faure et al., 2002 and Sautour et al., 2009). Japan (Yonemori et al., 2002). Greece (Panagopoulou et al., 2002 and Kuleta et al., 2009). Thailand (Saichna et al., 2008). Poland (Augustowska and Dulkiewicz, 2006, Gniadek and Macura, 2007). Iran (Shadzi \& Chadeganipour, 1996). Nigeria (Ekhaise et al., 2008). Korea (Kim et al., 2009). Czech Republic (Vackova et al., 2006). USA (Falvey and Streifel, 2007). Republic of China (Wu et al., 20oo). and several other.

Indoor airborne fungi exposure frequently causes adverse human health effect with injury to and dysfunction of multiple organs and systems including: respiratory, nervous, immune, hematological systems and skin. Indoor fungi are also common causes of life threaten systematic infections in immunocompramized patients (Curtis et al., 2004; Reedy et al., 2007). reported that fungi are important infections agents of both immunocompromised and immuno-competent in addition to immuno-suppressed individuals.

The development of medicine, surgery and transplantology in the last thirty years has caused a dramatic increase in the number of immuno-compromised individuals who are more susceptible to fungal infections (Kuleta et al., 2009). Fungi cause adverse human health effects through three specific mechanisms: generation of a harmful immune response, direct infection by the organism and toxic-irritant effects from fungal metabolites (Bush et al., 2006).

In this study Aspergillus was appeared with high frequency on all media used as airborne fungus with frequenciy ranged from 66.67 to $100 \%$, while its density fluctuated between $0.24-16.8 \%$.

The mortality in systemic aspergillosis is high as compared with other systemic mycoses (Gniadek and Macura, 2007). Most Aspergillus infection occurs via inhalation. The tiny spores of this genus readily invade upper and lower airways and may produce lung aspergillosis in risk group patients (Lutz et al., 2003; Gangneux, 2004; GarnachoMontereo and Amaya-villax, 2006).

Penicillium spp. was isolated as airborne fungus with high or moderate frequency on the different mycological media used and their densities ranged from 4.54 to $9.03 \%$ while their frequencies fluctuated between 58.33 and 83.33 using the four media. (Haleem khan et al., 2009). reported that Penicillium species cause infections in humans and the disease is known as penicillosis. It is acquired by inhalation and results in initial pulmonary infection, followed by fungemia.

Cladosporium was recorded with very high densities and frequencies in all the time of exposures in the atmosphere of all the 12 I.C.U. It was appeared with densities ranged from 43.04-80.3\%. Also, it was recorded in $100 \%$ of isolation cases. It was represented by $C$. cladosporioides and $C$. herbarum. The both species were isolated with high 
densities in $100 \%$ of isolation cases. These results are in harmony with those recorded by (Sautour et al., 2009). in France. They found that in outdoor samples, Cladosporium was the dominant genus (55\%). Also, they recorded the presence of Cladosporium with the highest level in spring and summer in the haematological units. (Faure et al., 2002). observed the presence of Cladosporium with $16 \%$ of total fungi in the haematologic hospital of Grenoble, France. Also Wu et al., (2000). isolated Cladosporium with $19.8 \%$ in one Asian hospital.

Fusarium was appeared with low densities and moderate or high frequencies in all cases. Their densities were ranged from $0.93-3.44 \%$ as airborne fungus in I.C.U. On the other side, their frequencies were ranged from $29.17-58.33 \%$. It was represented by two species named $F$. solani and $F$. oxysporum.

Sautour et al., (2009). isolated the airborne fungi from outdoor air and indoor two haematological units in a France hospital and recorded Fusarium with low frequency in all cases. Fusarium species were reported as causative agents of superficial and systemic infections in humans (fusariosis) (Howard, 2003). Fusarium species also produce several kinds of mycotoxins such as zearalenone, fumonisins and trichothecenes (Austen et al., 2001).

The other species that had been isolated with low or rare levels, they were reported to have adverse health symptoms. (O'Hollaren et al., 1991). recorded that A. alternate spores implicated in serious cases of respiratory arrest in Children and young adults. (Curtis et al., 2006). reported that the Stachybotrys exposed adults have noted a significantly higher incidence of health problems such as lower airway problems, wheezing, skin \& eye irritation and chronic fatigue. The role of infections caused by mould Mucor and Rhizopus in severely ill patients at intensive care units is increasing. The fungi may invade patients with inhaled air as well as through the diagnostic equipment (Gniadek and Macura, 2007).

\section{Conclusion}

Generally, it is not surprising that large amounts of fungi specially belonging of Aspergillus, Cladosporium, Penicillium, Fusarium, Alternaria, Rhizopus and several other fungal genera were recorded in the indoor air tested of different I.C.U. in Assiut university hospitals because that fungal genera is ubiquitous. Even though it is harmless for healthy people, it may be dangerous for the patients of risk groups (mmuno-compromised and immunocompetent in addition to immuno-suppressed individuals), including those treated in surgical wards and intensive care units. Therefore, it appears that indoor air monitoring focused in the presence of these and other fungi is an important procedure in wards where risk group patients are treated. Such a procedure should be routine in Assiut university hospitals or other and particularly at intensive care units.

\section{References}

Alberti, C., Bouakline, A., Ribaud, P., Lacroix, C., Rousselot, P. and Leblanc, T. (2001). Relationship between environmental fungal contamination and the incidence of invasive aspergillosis in haematology patients. J Hosp Infect; 48: 198-206.

Anderson, K., Morris, G., Kennedy, H., Croall, J., Michie, J., Richardson, M.D. and Gibson, B. (1996). Aspergillosis immunocompromised pediatric patients: association with building hygiene, design, and indoor air. Thorax 51, 256-61.

Augustowska and Jacek, D. (2009). Variability of airborne microflora in a hospital ward within a period of one year. J. Ann Agric Environ Med, 13, 99-106

Bush, Jay M., Portnoy, Andrew Saxon, Abba I.T. and Robert, A.W. (2006). The medical effects of mold exposure. J. Environmental and occupational respiratory disorders.

Curtis, M.S., CIH, Allen Lieberman M.D., Martha Stark M.D., William Rea, Marsha Vetter, M.D. (2004). Adverse Health Effects of Indoor Mould. J of Australasian College of Nutritional and Environmental Medicine Vol 23 No 1 April 2004.

Faure, O., Fricker-Hidalgo, H., Lebeau, B., Mallaret, M.R., Ambroise-Thomas, P. and Grillot, R. (2002). Eigh tyear 
surveillance of environmental fungal contamination in hospital operating rooms and haematologic units. J Hosp Infect; 50: 155-60.

Gangneux, J.P. (2004). Prevention of nosocomial invasive aspergillosis: protective measures and environmental surveillance. Mikol Lek; 11: 153-5.

Garnacho-Montereo, J., Amaya-Villar, R. (2006). A validated clinical approach for the management of aspergillosis in critically ill patients: ready, steady, go! Crit Care; 10: 132.

Gniadek, A., Macura, A.B. (2007). Intensive care unit environment contamination with fungi. J. Advances in Medical Sciences. Vol. 52.

Gould, J.C. (1970). Airborne pathogenic bacteria in a tissue transplant unit. In: Silver I.H. (Ed): Aerobiology. Academic Press, London, 62-76.

Haleem, K.S., Mohan K.C. Manoharachary, I.K., Kunwar, S.W. (2009). Isolation, identification and testing for allergenicity of fungi from airconditioned indoor environments. J., Aerobiologia, 25: 119-123

Herman, L.G. (1980). Aspergillus in patient care areas. Ann NY Acad Sci, 353, 140-146.

Hoekstra, E.S., Samson, R.A. and Summerbell, R.C. (2004). Methods for the detection and isolation of fungi in the indoor environment. In: Introduction to Food and Airborne fungi (eds:Samson R.A., Hoekstra E. S. and Frusavad, J.C.). pp. 298-305.

Kelsen, S.G. and McGuckin, M. (1980). The role of airborne bacteria in the contamination of fine particle nebulizers and the development of nosocomial pneumonia. Ann NY Acad Sci, 353, 218-229.

Kuhn, D.M, Ghannoum, M.A. (2003). Indoor mould, toxigenic fungi and Stachybotrys chartarum: infectious disease perspective. Clin Microbiol Rev 16: 144-172

Kuleta, Maria, Rapala-Kozik and Andrzej, K. (2009). Fungi pathogenic to humans: molecular bases of virulence of Candida albicans, Cryptococcus neoformans and
Aspergillus fumigates. Acta Biochimica Polonica. Vol. 56 No. 2/2009, 211-224

Li, C.S. and Hou, P.A. (2003). Bioaerosol characteristics in hospital clean rooms. Sci Total Environ, 305, 169176 flora in hospital air and hospital patients in India. In: Preusser HJ (Ed): Medical Mycology, 115-122.

Lutz, B.D., Jin, J., Rinaldi, M.G., Wickes, B.L., Huycke, M.N. (2003). Outbreak of invasive Aspergillus infection in surgical patients, associated with a contaminated airhandling system. Clin Infect Dis; 37(6): 786-93.

O’Hollaren, M.T., Yunginger, J.W., Offord, K.P., Somers, M.J., O'Connell, E.J., Ballard, D.J., and Sachs, M.I. (1991). Exposure to an aeroallergen as a possible precipitating factor in respiratory arrest in young patients with asthma. N Engl J Med; 324: 359-63.

Panagopoulou, J., Filioti, G., Petrikkosy, P., Giakouppiy, M.E., Farmaki, A., Kantay, H., Apostolakouz, A., Avlami, G., Samonisz and Roilides, Anatoliotakiz, E. (2002). Environmental surveillance of filamentous fungi in three tertiary care hospitals in Greece. J. of Hospital Infection. 52: 185 \pm 191 Pages 3-8

Perdelli, F., Cristina, M.L., Sartini, M., Spagnolo, AM.,Dallera, M. And Ottria, G. (2006). Fungal contamination in hospital environments. Infect Control Hosp Epidemiol; 27: 44-7.

Rainer, J., Peintner, U. and Poder, R. (2001). Biodiversity and concentration of airborne fungi in a hospital environment. Mycopathologia, 149, 87-97.

Reedy, Robert, J. Bastidas, and Joseph, H. (2007). The Virulence of Human Pathogenic Fungi: Notes from the South of France. Cell Host \& Microbe.

Sautour, N., Sixt, Frédéric Dalle, Coralie L'Ollivier, Vitalie Fourquenet Céline Calinon, Kusum Paul, Stéphanie Valvin, Alix Maurel, 
Serge Aho, Gérard Couillault, Claire Cachia, Odile Vagner, Bernadette Cuisenier, Denis Caillot, Alain B. (2009). Profiles and seasonal distribution of airborne fungi in indoor and outdoor environments at a French hospital. J. Science of the Total Environment 407, 3766-3771.

Schabrun, S. and Chipchase, L. (2006). Healthcare equipment as a source of nosocomial infection: a systematic review. J Hosp Infect 63, 239-45.
Singh, N. and Paterson, D.L. (2005). Aspergillus infections in transplant recipients. Clin Microbiol Rev; 18: 44-69.

Vanden Bergh, M.F.Q., Verweij, P.E., Voss, A. (1999). Epidemiology of nosocomial fungal infections: invasive aspergillosis and the environment. Diagn Microbiol Infect Dis 34: $221-227$

\section{الملخص العربي}

\section{الأحياء الفطرية للهواء الداخلي لوحدات العناية المركزة في مستثفيات جامعة أسيوط}

$$
\begin{aligned}
& \text { '. ب. ب. أبو النصر '، عبد الناصر أ. زهرى' و إيناس م. عامر' }
\end{aligned}
$$

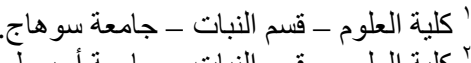

$$
\begin{aligned}
& \text { ' كلية العلوم - قسم النبات - جامعة أسيوط. }
\end{aligned}
$$

تمت دراسة تلوث هو اء وحدات العناية المركزة بمستشفيات جامعة أسيوط. تم تجميع العينات باستخدام طريقة ترسيب

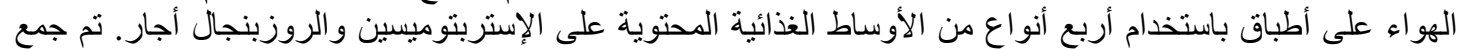

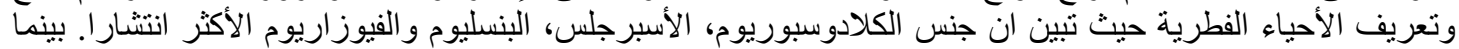

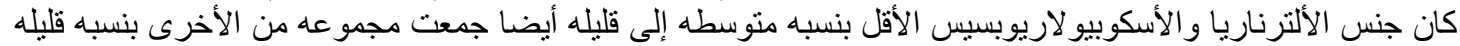

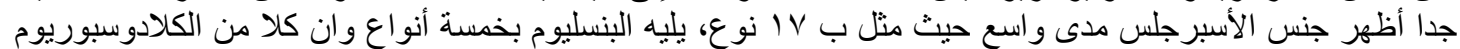

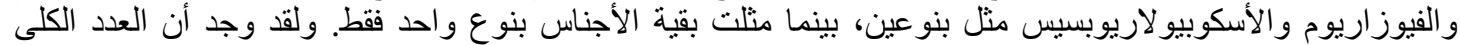

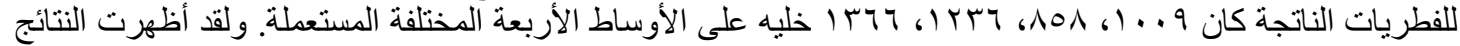

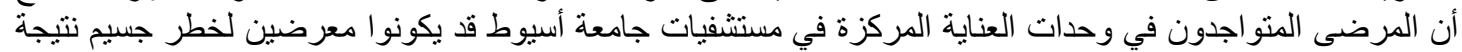

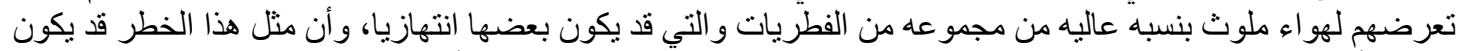
مميتا للأشخاص ذوى المناعة المنخفضة والمفترض تو اجدهم فى جو خالي تماما من أب تلوث. 